\title{
Enajenación de parcelas no utilizables: Problema que plantea la existencia de huecos sobre las mismas
}

\author{
por \\ FRANCISCO J. LLISET BORRELL
}

Sumario: I. Introducción: A) Concepto de las parcelas no utilizables. B) Su enajenación.-II. Planteamienlo del problema.-III. Soluciones: A) Doctrina tradicional. B) Postura que se mantiene: a) Formas de utilización de los bienes de dominio público. b) Conclusiones.

\section{INTRODUCCIÓN}

Es el tema de los "sobrantes de vía pública», sobre todo en los Míunicipios rurales, de evidente actualidad, debido, probablemente, al impacto que el progreso en los estudios urbanísticos - reflejado entre nosotros por la llamada Ley del Suelo-ha producido en la conciencia de los administradores, pese al esfuerzo de adaptación que para ellos suponen, según García de Enterría (1), las novedades introducidas por la citada Ley en la situación anterior. Claro está que ya en el pasado siglo se inició, en nuestra patria, el proceso legislativo del urbanismo con las leyes de ensanche y reforma interior de poblaciones (2), pero, aparte

(1) La Ley del Suelo y el futuro del Urbanismo, conferencia incluida en el libro del autor, Probienas actíales de Réginen local. aInstituto García Oviedop. Universidad de Sevilla, 19 ə̆8.

(2) Gircí. de Externí., op. cit., pág. 97. 
de que todavía se trataba de lo que Gabriel Alomar (3) ha llamado planeamiento restrictivo-que impone determinadas condiciones a la utilización de los terrenos, ejerciendo una acción puramente legislativa-, lo cierto es que en los Municipios rurales, e incluso en las pequeñas ciudades, fué escasa, y a veces nula, la intervención (4) en el campo urbanístico, pues los propietarios gozaban de la más amplia libertad al edificar, a menudo sin la previa licencia, dando lugar, de este modo, a un verdadero caos de edificaciones que, ahora precisamente, se intenta corregir, al sentirse la necesidad de aplicar los nuevos criterios racionales de ordenación urbana, bajo el signo de un planeamiento constructivo (5).

\section{A) Concepto de las parcelas no utilizables.}

Son parcelas no utilizables-denominación que ha sustituido a la más clásica de sobrantes de vía pública-, "aquellas porciones de terreno, propiedad de las Entidades locales que, por su reducida extensión, forma irregular o emplazamiento no fueren susceptibles de uso adecuado (art. 7. ${ }^{\circ}, 2$, del Reglamento de Bienes de las Corporaciones locales).

Aunque sea a los solos efectos de autorizar la consignación del precio de dichas parcelas como ingreso de presupuestos ordinarios, el artículo $6 .^{\circ}$ del Reglamento de Haciendas locales las define como "aquellos terrenos que, al urbanizar o reformar vías públicas municipales, no resultaren susceptibles de edificación, por no tener la superficie mínima que para ello exijan las Ordenanzas locales o las disposiciones generales sobre urbanismon.

$\mathrm{Su}$ naturaleza jurídica es la de bienes de propios (6), lo que postula-dado que originariamente habían sido terrenos unidos

(3) Gabriel Alomar, Comunidad planeada. aInstituto de Estudios de Administración Localo, Madrid, 1955.

(4) Para la distinción entre intervencionismo estatal e intervencionismo admitistrativo, vid. Garrido Falla, en Transformaciones del Régimen administrativo, aInstituto de Estudios Políticosn, Madrid; 1956.

(5) Gabriel Alomar, op. cit., pág. 171.

(6) Ait. 7, 1, del Reglamento de Bienes de las Corporaciones locales. 
sin solución de continuidad a la vía pública, $y$, por tanto, de uso público-un cambio de calificación jurídica. Por esto, no basta para que podamos aplicar a las enajenaciones de los terrenos determinados en el artículo $7 .^{\circ}, 2$, las normas reguladoras de las parcelas no utilizables, con que se den aquellos supuestos fácticos, sino que es también precisa la existencia de un nuevo elemento: la declaración de desafectación del uso público por el órgano competente (7), o, siquiera, la desafectación tácita (8).

\section{B) Su enajenación.}

Si las parcelas no utilizables son bienes de propios, quedarán sujetas al mismo régimen jurídico que éstos, y serán, por tanto, enajenables (9). No obstante, el Reglamento de Bienes contiene ciertas peculiaridades respecto de la enajenación de los sobrantes de vía pública, que obedecen a sus propias características y finalidad.

El derogado Reglamento de Organización y Funcionamiento de los Ayuntamientos se remitía a la vieja Ley de Parcelas del Estado de 17 de junio de 1864 y a la Instrucción de 20 de marzo de 1865 , pero esa referencia desaparece en todos los textos de la legislación vigente, que por uno u otro motivo se ocupan de las parcelas que estudiamos (10).

Siguiendo el esquema del profesor González Pérez, en su trabajo "La enajenación de los bienes inmuebles de las Entidades

(7) Dentro de la desafectación expresa, deben distinguirse dos supuestos: 1. La desafectación declarada, previo expediente, por la Corporación, mediante acuerdo adoptado con el quorum del artículo 303 de la Ley de Régimen local (art. 8.॰ 1 y 2, del Reglamento de Bienes). 2. Cuando las parcelas surjan de un plan o proyecto de ordenación urbana, debidamente aprobado por la Comisión provincial de Servicios técnicos $\supset$ por la central de Urbanismo.

(8) Consagrada en el apartado quinto del artículo 8.० del Reglamento de Bienes, tiene su precedente doctrinal en GARcfa DE ENTERriA, Dos estudios sobre la usucapibib en Derecho administrativo. aInstituto de Estudios Políticos», Madrid, 1955.

(9) Vid. articulos 188 y 189 de la Ley de Régimen local.

(10) Así en el artículo 123, 11, del Reglamento de Organización, Funcionamiento y Régimen jurídico; artículo 6 del Reglamento de Haciendas locales y artículos 7, 28, 100 y 101 del Reglamento de Bienes. 
loca'es..., (11), y limitándonos a las peculiaridades de la enajenación de las parcelas no utilizables, pues en aquel estudio encontrará el lector un desmenuzado análisis de la enajenación de los bienes inmuebles en general, señalaremos dos siguientes requisitos :

a) Requisitos subjetivos.

En cuanto a la competencia-único extremo que ofrece alguna especialidad-, quiebra el principio general que la atribuye al Ayuntamiento en materia de enajenación de inmuebles, reservándola en estos supuestos, como excepción, a la Comisión municipal. Permanente, en los Municipios a los que corresponda este órgano (art. $122 h$ ) de la Ley de Régimen local y art. 123, 11, del Reglamento de Organización, Funcionamiento y Régimen jurídico).

Más importante nos parece, en este mismo terreno de los requisitos subjetivos, por las cuestiones que plantea, lo referente a quienes pueden adquirir las parcelas no utilizables: Si los demás bienes inmuebles de los Municipios pueden ser adquiridos por cualquier persona que reúna los requisitos que exigen las leyes civiles (12), los sobrantes de via pública, en principio, con base en el artículo 100 del Reglamento de Bienes, sólo pueden ser adquiridos por los propietarios de fincas colindantes.

No obstante, Marqués Carbó (13) afirma que "si las parcelas que no reúnen la condición de edificables tienen varios propietarios colindantes, el Ayuntamiento, discrecionalmente, puede adjudicarla a uno solo de dichos propietarios o distribuirla entre ellos por partes proporcionales a la superficie de terreno que tenga cada propiedad colindante, atendiendo siempre a razones en vista a formar solares edificables, y si la parcela no interesa a dichos propietarios, el Ayuntamiento puede enajenar directamente o mediante subasta, según sea el valor de la parcelan. Si

(11) Vid. Revista de Estudios de la Vida local, núm. 83.

(12) En los contratos de enajenación de bienes no son aplicables los artículos 4 y 5 del Reglamento de Contratación de las Corporaciones locales, que lo serán sólo, según González Pérez, op. cit., en los contratos de obras y servicios públicos.

(13) El Derecho local español, I, pág. 887. 
la parcela no es solicitada, en caso de único colindante-dice también Marqués-, el Ayuntamiento puede enajenarla directamente o mediante subasta, según sea el valor de la parcela.

A nuestro juicio, el Reglamento de Bienes fuerza a una solución distinta: las parcelas no utilizables están "pensadas" para los colindantes, nos atrevemos a decir, en todo caso. Estas enajenaciones no deben ser motivo de lucro para nadie, aunque de rechazo se lucre, a veces, el Municipio, y siempre los adquirentes. Con ellas no debe perseguirse otra cosa que el interés público, concretado en las necesidades urbanísticas, y este interés no podría ser satisfecho dada la definición, ya transcrita, del artículo $7 .^{\circ}$ del Reglamento de Bienes, por un no colindante. Aunque la parcela no interese a los que, según dictamen técnico, corresponda, el Ayun'tamiento no podrá venderla a un tercero, ya que, al no ser edificable aquélla, mal podría cumplir el interés público perseguido. Nos lleva a esta conclusión la referencia "al más racional criterio de ordenación del suelo, según dictamen técnicon, del párrafo $20^{\circ}$ del artículo 100 del Reglamento de Bienes, y sobre todo, su párrafo $3 .^{\circ}$, donde se prescinde de la voluntad del propietario colindante, elemento básico en el argumento de Marqués, y se atiende sólo a la voluntad de la A.dministración, que puede obligar al colindante a la adquisición de la parcela, también aquí, según dictamen técnico, so pena de verse privado, incluso, de la propiedad de su terreno.

Por otra' parte, estamos de acuerdo con Marqués en lo de que ei Ayuntamiento-la Comisión municipal Permanente, en su caso-podrá, discrecionalmente, adjudicar la parcela a uno solo de los colindantes o distribuirla entre ellos. Con todo, es necesario hacer una importante observación. A la vista de la expresión, "según dictamen técnico»-implicadora de un carácter vinculante del dictamen para la Administración municipal-, parece que el Ayuntamiento y, en su caso la Comisión municipal Permanente, no pueden actuar discrecionaimente en la adjudicación de sobrantes de vía pública, en el caso de que existan varios colindantes. Pero la reciente publicarción de la Ley de Procedimiento administrativo de 17 de julio de 1958, aplicable como supletoria al campo de la Administración local, según su artícu- 
Io $1 .^{\circ}, 4$, nos hace cambiar de opinión, al decir, en su artículo 85, 2 , que "salvo disposición expresa en contrario, los informes serán facultativos y no vinculantes).

El acto administrativo por el que se resuelve la adjudicación de una parcela no utilizable, si fueren varios los propietarios colindantes, es un ejemplo de lo que se ha llamado la wdiscrecionalidad técnica", es decir, cuestiones que han de resolverse a la vista de un juicio técnico, emitido por un órgano especializado de la Administración (14). Como consecuencia, el acto de adjudicación queda sustraído a la fiscalización de la Jurisdicción contencioso-administrativa, que no puede subrogarse en la apreciación de los criterios técnicos, tenidos en cuenta por la Administración al elegir, habida cuenta de que no puede manejar más técnica que la jurídica. Esto es así en el caso de que la Administración resuelva según dictamen técnico. Pero ¿y si-puesto que el dictamen no vincula al órgano administrativo competente-no lo hace ? Entonces, la resolución, en cumplimiento del artículo $43 c$ ) de la Ley de Procedimiento administrativo debe ser motivada, y si no se adecuase al interés público, concretado en el "más racional criterio de ordenación del suelo", podría ser objeto de recurso por desviación de poder.

b) Requisitos objetivos.

1. Bienes susceptibles de enajenación.

Para que sean aplicables las normas establecidas en el artículo 100 del Reglamento de Bienes, es preciso que se trate de porciones de terreno que reúnan las circunstancias señaladas en el artículo $7 .^{\circ}, 2$, del mismo Reglamento, y que hayan sido desafectadas del uso público, de conformidad con el artículo $8 .^{\circ}$.

2. Causa de los contratos.

Es aquí aplicable el artículo 11 del Reglamento de Contratación de las Corporaciones locales, pero no estamos de acuerdo con González Pérez (15)—si bien habla este autor en términos

(14) Garrido Falla, Tratado de Derecho administrativo, $I$. Instituto de Estudios Politicos», Madrid, 1958, pág. 209.

(15) Enajenación de bienes inmuebles de las Entidades locales en el Reglamento de Bienes y de Contratación, en Revista DE Estudios DE LA VIdA Local, núm. 83. 
generales-, para el que, wde los supuestos previstos en dicho artículo, parece ser que, en los casos de contratos traslativos de dominio, la "mayor economía" constituirá la causa de los mismos». Creemos, por el contrario, que, en el supuesto que nos ocupa, el interés público viene determinado por la umejor calidad", según lo manifestado por nosotros más arriba (16).

c) Requisitos formales.

Quiebra aquí el principio general de la contratación por subasta, señalándose en el repetido artículo 100, 1, que "las parcelas no utilizables a que alude el artículo $7 .^{\circ}$, serán enajenadas por venta directa al propietario o propietarios colindantes o permutadas con terrenos de los mismos". Discrepamos de la opinión sustentada por Marqués (17), de que cabe la venta en pública subasta, con carácter normal, cuando se niegue a adquirir aquél o aquéllos a quienes corresponda, debido a la imposibilidad de que, por los motivos técnicos aludidos, las parcelas sean adjudicadas a un no colindante.

\section{Planteamiento DeL problema}

No presenta ninguna dificultad el caso de existencia de un solo colindante, si, como hemos dicho, debe adjudicársele, a él precisamente, la parcela, salvo que se niegue a adquirirla, en cuya hipótesis procede la expropiación.

Nos interesa sólo el supuesto de existencia de varios colindantes, siempre que sobre el terreno sobrante se hallen abiertos huecos, sean puertas, ventanas o cualesquiera otros. Puede, entonces, ocurrir que la parcela o parcelas se adjudiquen al propietario o propietarios de edificios cuyos huecos se abran, precisamente, sobre la porción a ellos adjudicada. Pero también pue-

(16) La causa que debe mover a la Administración municipal, al adjudicar una parcela sobrante de vía pública, no debe ser una amayor economías, en cuyo caso no sería justificable la excepción del artículo 100,1 , del Reglamento de Bienes, al principio general de subasta como forma de la contratación de los Entes públicos, sino el mejor modo de satisfacer las exigencias urbanisticas.

(17) $O p$. cit., misma página. 
de ocurrir, dando lugar al interesante problema que nos proponemos estudiar, que las parcelas se adjudiquen a propietario distinto de aquellos que ostentan huecos sobre ellas, prescindiendo de si los adjudicatarios los tienen también. El problema se presenta prácticamente en los siguientes términos: ¿ Puede el que ha adquirido una parcela sobrante de vía pública, sobre la que otro colindante tiene aberturas, tapiar éstas cuando edifique, o, por el contrario, está obligado a retroceder el espacio señalado por las leyes civiles?

\section{SOLUCIOnes}

Existen dos soluciones: la tradicional o civilista y la moderna o administrativista. Para la primera existe, en el supuesto considerado, una servidumbre civil sobre el terreno sobrante. Para la segunda, que es la que propugnamos, no sólo no existe una carga real de derecho civil, sino ni siquiera un derecho real administrativo.

\section{A) Doctrina tradicional.}

Es la postura mantenida tradicionalmente por nuestro Tribunal. Supremo. Algunos sectores de la doctrina, nos dice Martínez Useros (18), han considerado estas situaciones (19) como com. prensivas de verdaderas servidumbres de Derecho civil, a cargo del dominio público y en beneficio de la propiedad privada. Es lógico, pues, siguiendo la orientación de este sector doctrinal, que si el dominio público es susceptible de servidumbres de Derecho civil, tanto más pueden serlo los terrenos que se han desafectado del uso público. Es claro ejemplo dəesta posición, Pella y Forgás (20) al decir que “... es de tal naturaleza la condición

(18) Notas al Derecho administrativo de Garcín Oviedo. Madrid, 1955.

(19) Se refiere el autor citado a la situación creada al abrir huecos a la calle un propietario ribereño.

(20) Derecho civil de Cataluña, II. Barcelona. 
de la vía pública, que: aun cuando deje de serlo, subsiste el derecho a vistas y luces sobre la propiedad particular que venga a emplazarse en el terreno de la antigua vían. Así lo reconoció el Tribunal Supremo en la sentencia de 5 de abril de 1898 , en que se sienta que "los propietarios colindantes con una vía pública pueden abrir sobre ella huecos de luces y vistas, si bien con sujeción a las disposiciones que regulan ese disfrute, adquiriendo así un derecho que constituye verdadera servidumbre sobre el terreno de la vía pública al convertirse en propiedad particular, a menos que se la libere de tal gravamen, en virtud de una causa justan.

La crítica de esta tendencia es bien fácil. Se les puede objetar a sus seguidores lo siguiente: a) En el terreno jurídico: $1 .^{\circ}$, el dominio público no es susceptible de gravámenes de Derecho civil (21), y $2 .^{\circ}$, siendo cierto lo anterior, no puede nacer servidumbre de Derecho civil, al transformarse la vía pública en parcela no utilizable y ser enajenada a un particular, si no se da alguno de los modos de adquirir establecidos en los artículos 537 y siguientes del Código civil. b) En el terreno urbanístico: es. incompatible con "el más racional criterio de ordenación del suelon, el hecho de dejar pasillos entre las edificaciones surgidas. sobre las parcelas no edificables y los demás propietarios colindantes, poseedores de huecos, a los cuales, precisamente por razones urbanisticas, no se les ha adjudicado porción alguna de terreno situada ante sus aberturas.

\section{B) Postura que se mantiene.}

Deriva nuestra postura de la crítica que hemos hecho de la: postura tradicional. Distinguiremos, pues, como allí, dos extremos: el primero, nos llevará al estudio de las formas de aprovechamiento del dominio público, y el segundo será tratado en las conclusiones de este trabajo.

(21) MARtísez Useros, Improcedencia de servidumires sobre el dominio público, en astudios en honor del Profesor Garcia Oviedos, tomo I. 
a) Formas de utilización de los bienes de dominio público.

El Reglamento de Bienes, en su artículo 59, recogiendo la doctrina de Ballbé (22), distingue entre uso normal y anormal, y, de otro lado, entre uso común y privativo, atendiendo, respectivamente, al destino de la cosa y a la intensidad del uso.

Uso común es el que corresponde por igual a todos los ciudadanos, indistintamente, de modo que el uso de unos no impida el de los demás interesados, y se estimará general, cuando no concurran circunstancias singulares (ej.: sacar agua de un cauce), y especial si concurrieran circunstancias de este carácter, por la peligrosidad, intensidad del uso o cualesquiera otras semejantes (ej.: navegar por un río).

Uso privativo es el constituído por la ocupación de una porción del dominio público, de modo que limite o excluya la utilización por los demás interesados (ej.: instalación de kioscos en la vía pública) (23).

¿Qué clase de utilización del dominio público supone la existencia de huecos abiertos a la calle?

A nuestro juicio, se trata de un uso común especial. Aparte de que es perfectamente encasillable en el número $1 ; b$ ) del artículo 59 del Reglamento, el tratamiento que, en nuestro Derecho, se da al supuesto que contemplamos, nos lleva a aquella afirmación.

El artículo 584 de! Código civil consagra el derecho civil a abrir ventanas sobre la vía pública, si bien este derecho está regulado o condicionado, como reconoce el Tribunal Supremo, por la Administración. Pero si es cierto que se trata de un derecho civil a abrir huecos a la calle, el hecho de abrirlos no hace nacer derecho alguno sobre ella, ni civil, porque no caben derechos de esta naturaleza sobre el dominio público, ni administrativo, porque no estamos en presencia de una concesión, sino, simple-

(22) Apuntes tomados de las explicaciones de cátedra.

(23) Garcfa Oviedo incluye este ejemplo, erróneamente a nuestro juicio, dentro de las autorizaciones, en vez de considerarlo como concesión. 
mente, de una autorización o licencia (24). La diferencia entre una y otra categoría jurídica radica, siguiendo la moderna doctrina, en que la concesión da lugar a un derecho real administrativo (25), mientras que la autorización, como dice Villar Palasí (26), no crea derecho; se limita a dar entrada en el mundo de las relaciones jurídicas a un derecho ya existente, pero dormido o potencial en su eficacia por la presión impeditiva de obstáculos policiales. A mayor abundamiento, Fleiner, citado por Martínez Useros (27), dice que la colindancia con la vía pública no crea derechos subjetivos especiales cerca del Estado o del $\mathrm{Mu}$ nicipio. Lo que ocurre es que la situación de la finca le coloca en la situación de aprovechar el uso público con más frecuencia que los demás. El colindante no tiene un mayor derecho, sino un mayor interés económico en el uso de la cosa pública.

b) Conclusiones.

De todo lo expuesto, cabe deducir que no se puede privar a un propietario del derecho a abrir huecos a la calle, mientras ésta no sea desafectada del uso público, siempre que se cumplan las condiciones establecidas, a cuyo efecto deberá solicitar la oportuna licencia, que producirá, una vez obtenida, el efecto de eliminar los obstáculos policiales existentes. Se trata, repetimos, de un derecho civil, derivado de la colindancia de la propiedad y la vía pública, sin que el hecho de su ejercicio genere un derecho real administrativo sobre la calle.

$\mathrm{Si}$, por cualquier circunstancia, se altera la calificación jurídica de la porción de vía pública colindante, no existiendo antes un derecho real sobre ella, tampoco puede surgir ahora una servi-

(24) Villar Palasi, voz Concesiones, Nuevos Estudios Juridicos», tomo IV, Vid. también artículos 60,61 y 62 del Reglamento de Bienes.

(2j) González Pérez, Los derechos reales administrativos, en Revista Crítica de Derecho Inmobiliarion, marzo-abril, 1957; Villar Palasf, op. cit.

(26) Villar Palasf, op. cit.

(27) Notas al Derecho Administrativo de Garcí Oviedo, ed. 1955. 
dumbre de derecho civil, como por arte de magia. La alteración de la calificación jurídica del terreno sólo tiene relevancia en cuanto que, mientras es vía pública, no puede ganarse por prescripción, al contrario de si se ha convertido, expresa o tácitamente, en parcela no utilizable. En consecuencia, desafectada del uso público una parcela a la que se abren puertas o ventanas de un edificio colindante, de propietario distinto, éste no puede invocar frente al Ayuntamiento, ni frente al adjudicatario de la parcela, derecho subjetivo alguno.

Nuestras últimas afirmaciones podrían llevar a pensar que los titulares de los huecos sobre parcelas adjudicadas a otro no deben ser en ningún caso indemnizados por la Administración, pudiendo ésta vender, en cualquier supuesto, sin necesidad de expropiación, y pudiendo los adjudicatarios, por consiguiente, edificar tapiando los huecos. Pero ello daría lugar, evidentemente, a si= tuaciones de injusticia notoria. Imagínese el caso del propietario de un edificio con una única puerta a la parcela que, por razones urbanísticas, debe venderse a otro colindante. Es cierto que dicho propietario no ha adquirido ningún derecho real sobre lo que fué calle, a menos que hubiera transcurrido el plazo de prescripción señalado por las leyes civiles a partir de la desafectación expresa o tácita, pero no se le puede negar la titularidad de un interés legítimo (28). La vigente Ley de Expropiación forzosa de 16 de diciembre de 1954 comprende, según su artículo $1 .^{\circ}$, "cualquier forma de privación singular de la propiedad privada o de derechos o intereses patrimoniales legítimos...n. Esta alusión a los intereses legítimos debe entenderse, dice García de Enterría (29) como un "concepto válvula", cuya modulación se confía a la prudencia de los Tribunales. Quiere decirse-continúa-que no todos los llamados intereses legítimos en otras aplicaciones tendrán

(28) No deben confundirse los intereses legítimos en el plano del derecho material y el ainterés legítimo para accionar o recurriro, como concepto procesal. En el primer sentido, artículo $1^{\circ}$ de la Ley de Expropiación forzosa; en el segundo, artículo 28,1$)$ a) de la Ley sobre la Jurisdicción contencioso-administrativa y el artículo 23, b) de la Ley de Procedimiento administrativo.

(29) Garcfa de EnTERrí, Los principios de la mueva Ley de Expropiación forsosa, pág. 54 . 
cabida en la hipótesis de la Ley; intereses legítimos a los efectos de esta Ley (construcción necesaria, que se remite a la Jurisprudencia), serán sólo aquéllos sumamente calificados, cuyo sacrificio imponga la consecuencia de una indemnización. Un ejemplo podría ser el caso más arriba señalado como de notoria injusticia. Por el contrario, no daría lugar a indemnización la hipótesis de un edificio con varias puertas y ventanas a una o más calles de tránsito, al desafectarse del uso público la porción de terreno correspondiente a otra fachada en la que también existe una pequeña "rajalera" que permaneció siempre cerrada y que no reportaba ninguna utilidad. Claro está que entre los dos ejemplos citados, caben muchas matizaciones, que, como dice Enterria, hay que dejar a la Jurisprudencia.

En definitiva, pues, podemos sentar las siguientes conclusiones:

1. Que el propietario de un edificio con huecos sobre una parcela no utilizable adjudicada a otro no tiene ningún derecho real sobre ella, a menos que haya transcurrido, desde la desafectación, el plazo marcado por las leyes civiles para la usucapión, pero puede ser titular de intereses patrimoniales legítimos, en cuyo caso procederá o no, según la entidad del interés, la indemnización (30).

2. Realizada la expropiación del interés legítimo, el comprador de la parcela podrá edificar tapiando los huecos cuando edifique. No mediando la expropiación, aun en el supuesto de que no procediese indemnizar por la poca entidad del interés-extremo cuya decisión incumbe a los Tribunales-, entendemos que la edificación por el comprador-beneficiario de la expropiación, cuyo expediente es ineludible-constituye una "vía de hecho", siendo perfectamente aplicable el artículo 125 de la Ley de Expropiación forzosa, es decir, que el titular de los huecos y ventanas podrá utilizar, además del recurso de reposición contra el acuerdo de adjudicación del Ayuntamiento o Comisión munici-

(30) García de Enterría, op. cit. pág. 174, distingue entre expropiación y responsabilidad. Vid. también Garrido Falla, Teoría de la indemnización en Derecho público, en Estudios dedicados al Profesor Gascón y Marín». 
pal Permanente y consiguiente recurso contencioso-administrativo, los interdictos de retener y recobrar, ante los Tribunales ordinarios.

Bastará, para poner punto final a nuestro trabajo, con que señalemos las ventajas de nuestra postura sobre la tradicional, a saber:

1. La doctrina clásica, el particular adquirente, al existir sobre la porción comprada o permutada una servidumbre, ha de retroceder, al edificar, el espacio señalado por las leyes civiles, solución de todo punto incompatible, aparte de su incorrección desde el punto de vista técnico-jurídico, con las exigencias del moderno urbanismo, que no pueden quedar condicionadas por pretendidos derechos de carácter civil.

2. Aún admitiendo la necesidad, por razones urbanísticas, de que la Administración expropie los derechos de paso, luces o vistas, antes de vender a otro colindante a quien corresponda la parcela según dictamen técnico, se trataría de una fórmula rígida, que postula la indemnización en todo caso, por encontrarnos precisamente ante derechos, no ante intereses patrimoniales legítimos.

3. La postura que mantenemos salva los dos inconvenientes apuntados, al partir, en primer término, de una posición de prerrogativa de la Administración, sin que, en modo alguno, suponga un olvido de la garantía del particular, si bien hace posible esta garantía no ya por medio de técnicas privatistas, sino a través de una fórmula flexible, que determina, atendiendo a las particulares circunstancias de cada caso concreto, si procede o no la indemnización. 